\title{
¿De dónde salieron y a dónde se fueron? Migración interna de regiones de alta violencia en México en las últimas dos décadas
}

Oscar Rodríguez. El Colegio de la Frontera Norte, Chihuahua, México.

RESUMen | La violencia en México se incrementó desde 2007, cuando comenzó la Guerra contra el Narcotráfico por los enfrentamientos entre grupos criminales, lo que a su vez propició el aumento de la migración interna. A partir de técnicas de asociación espacial y de la matriz de origen-destino, en este estudio se presenta la relación entre los niveles de violencia y los flujos de migración interna en los municipios con mayores tasas de homicidios en el periodo 1995-2015. Los resultados muestran que las regiones noroeste, noreste y occidente de México, con altas tasas de violencia, experimentaron una asociación entre altas tasas de emigración y bajas tasas de inmigración interna, y que la mayor parte de los emigrantes de estas regiones se han dirigido a ciudades cercanas de tamaño mediano. Por tanto, el incremento de la violencia criminal en ańos recientes ha repercutido en la magnitud y lugares de destino de los migrantes de regiones con alta violencia.

PALABRAS CLAVE $\mid$ migración, violencia, regionalización.

ABSTRACT | Violence in Mexico has increased since 2007, when the Mexican Drug War began with clashes between criminal groups. In turn, this led to an increase in internal migration. Using spatial association techniques and the origin-destination matrix, this paper studies the relationship between levels of violence and internal migration flows in the municipalities with the highest homicide rates in the period 1995-2015. Results show that the northwest, northeast and western regions of Mexico, which are those with the highest rates of violence, experienced an association between high emigration rates and low rates of internal immigration, with most of the emigrants from these regions migrating to medium-sized cities. Therefore, the increase in criminal violence in recent years has had an impact on the magnitude and the destinations of internal migrants from regions with high violence.

KEYWORDS | migration, violence, regionalization. 


\section{Introducción}

La migración interna en México es causada por diferentes motivos sociales, económicos y demográficos. No obstante, las condiciones actuales de inseguridad por las que atraviesa el país, y en particular algunas regiones del norte y occidente han provocado el desplazamiento forzado de miles de familias que se ven obligadas a abandonar sus lugares de residencia habitual por el temor de ser víctimas de la inseguridad o violencia, para salvaguardar su vida y la de sus seres queridos.

Pese al incremento de la violencia desde la denominada Guerra contra el Narcotráfico (GCN) iniciada por el expresidente Felipe Calderón a finales de 2006 como resultado de los enfrentamientos entre las fuerzas armadas y los grupos del crimen organizado, y posteriormente de la división y enfrentamiento de los grupos criminales por el control de los territorios y las rutas de trasiego de drogas en México y hacia Estados Unidos de América (EUA), no fue sino hasta 2020 que se aprobó en la Cámara de Diputados el proyecto de ley sobre Desplazamiento Forzado Interno, en que se reconoce a las víctimas de este fenómeno. Hasta la fecha, sin embargo, aún se carece de cifras oficiales acerca de su magnitud y ubicación, y tampoco de las necesidades, carencias y vulnerabilidades a las que están expuestos los migrantes no económicos.

El Internal Displacement Monitoring Centre (IDMC, 2020) calcula que hasta diciembre de 2019 había en México alrededor de 345 mil desplazados internos por conflictos y violencia, en tanto que a partir de la Encuesta Nacional de la Dinámica Demográfica (ENADID) 2014, se estima que el 1\% de los migrantes internacionales y el 6\% de los migrantes internos entre 2009 y 2014 habían migrado por cuestiones de inseguridad y violencia (Instituto Nacional de Estadística y Geografía [INEGI], 2015).

Por otro lado, diversos informes y trabajos (Botello, Dávila-Cervantes \& Pardo, 2019; Consejo Nacional de Población [CONApo], 2019; Internal Displacement Monitoring Centre [IDMc], 2010, 2020; Schmidt, Cervera-Gómez \& Botello Mares, 2017), además de datos del INeGi (2020), muestran que las regiones con mayores problemas de violencia criminal desde el inicio de la GCN se han concentrado particularmente en las entidades de Chihuahua, Sinaloa, Durango, Nuevo León, Tamaulipas, Guerrero y Michoacán, en las que se han registrado desplazamientos masivos por cuestiones de inseguridad y violencia.

Por tanto, los altos niveles de violencia criminal pueden llegar a propiciar la migración de cientos e inclusive miles de familias dentro y fuera de México, particularmente en regiones en disputa por grupos criminales, y en particular por los cárteles de drogas.

\section{Violencia criminal en México}

La evolución y crecimiento de la violencia criminal al interior de México en las últimas dos décadas responde particularmente a los enfrentamientos armados entre grupos criminales y contra las fuerzas armadas por el control de los territorios de cultivo, producción, distribución y venta de drogas en el país, así como de las rutas 
y puertos de acceso terrestre al mercado de drogas en EuA. Si bien México había sido desde mediados del siglo xx uno de los principales países productores de marihuana para el mercado estadounidense, no fue hasta los ańos noventa que el declive de la ruta del Caribe usada por los cárteles de drogas colombianos para introducir cocaína a Florida propició una alianza entre cárteles para ampliar las rutas terrestres de cocaína por diferentes puntos de acceso a lo largo de la frontera norte de México (Secretaría de Gobernación [SEGob], 2010).

En un principio, el cultivo de marihuana y amapola en México se concentraba en la región noroeste, particularmente en las sierras de Durango, Chihuahua y Sinaloa -en lo que la Administración para el Control de las Drogas de los Estados Unidos (DEA, por sus siglas en inglés) denominó en los años sesenta como Triángulo Dorado-, cuya ubicación, orografía, clima, además de las condiciones sociales y económicas de su población, propiciaron desde la Segunda Guerra Mundial (sGM) el cultivo de marihuana y adormidera para la producción de distintos tipos de drogas con destino a EUA (Morales Tenorio, 2019). ${ }^{1}$

Posteriormente, en los años ochenta, tras la presión del gobierno estadounidense al mexicano, se combatió a algunos de los cárteles de drogas ubicados en el Triángulo Dorado. Esto provocó la dispersión y ampliación de las regiones de producción de drogas a otras entidades del país, particularmente al occidente de México, en la llamada Tierra Caliente, comprendida por territorios de la sierra de Guerrero y Michoacán, donde ya se sembraba marihuana desde los años cuarenta y donde, debido a estos acontecimientos, se amplió el cultivo de marihuana y amapola, y posteriormente la producción de diversos tipos de drogas sintéticas (Guerra Mazo, 2018).

A final de los ańos ochenta, tras la captura de algunos de los principales capos de drogas mexicanos, como Miguel Ángel Félix Gallardo y Rafael Caro Quintero, del extinto cártel de Guadalajara, se dio una ruptura del pacto vigente entre los distintos cárteles mexicanos activos en esos años, lo que propició disputas entre ellos por el control de los territorios de producción y puertos de acceso al mercado de drogas estadounidense (InSight Crime, 2020). Sin embargo, no fue hasta finales de 2006 que el expresidente Felipe Calderón puso en marcha la denominada "Guerra contra el Narcotráfico", consistente en el enfrentamiento de las fuerzas armadas del Ejército y de la Policía Federal contra algunos de los principales cárteles de drogas, lo que elevó la violencia del país hasta sus mayores niveles como resultado de la división de esos cárteles tras la captura o muerte de sus principales líderes, generando disputas por el control de las organizaciones, territorios y rutas de drogas (Comisión Mexicana de Defensa y Promoción de los Derechos Humanos [смDpdH], 2014).

De acuerdo con el autor, la demanda de opiáceos en EuA resultó del tratamiento de los soldados norteamericanos con morfina durante la sGM, lo que provocó su adicción a distintas sustancias psicotrópicas, entre ellas la marihuana y la heroína. El problema se agravó con las guerras de Corea y de Vietnam en los ańos sesenta, incrementando la demanda de marihuana y de otros tipos de drogas en la región. 


\section{FIGURA I | Tasas de homicidios por cada 100 mil habitantes en las regiones de} México (1990-2018)

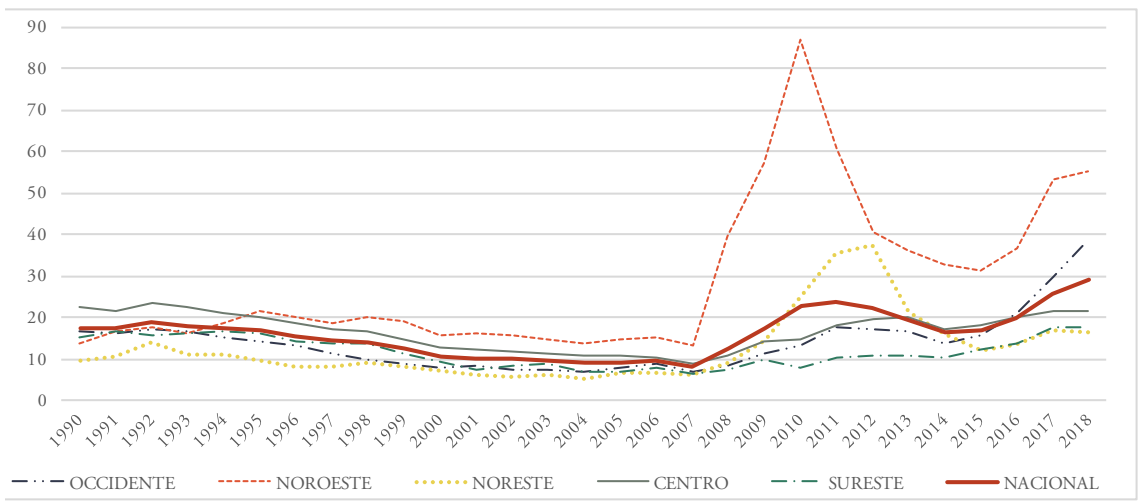

NOTA: SE DEFINE A LAS REGIONES COMO SIGUE: OCCIDENTE (AGUASCALIENTES, COLIMA, GUANAJUATO, JALISCO, MICHOACÁN, NAYARIT, QUERÉTARO Y ZACATECAS), NOROESTE (BAJA CALIFORNIA, BAJA CALIFORNIA SUR, CHIHUAHUA, SINALOA Y SONORA), NORESTE (COAHUILA, DURANGO, NUEVO LEÓN, SAN LUIS POTOSí Y TAMAUlipas), CENTRO (CIUDAD DE MÉXICO, ESTADO DE MÉXICO, guerrero, hidalgo, morelos, puebla y tlaxcala), y sureste (CAmpeche, Chiapas, OAXACA, QUINTANA ROO, TABASCO, VERACRUZ Y YUCATÁN)

FUENTE: ELABORACIÓN PROPIA A PARTIR DE LA REGIONALIZACIÓN DEL CNS (2OI3) Y LOS REGISTROS ADMINISTRATIVOS DEL INEGI (2020)

El incremento de la violencia a partir de 2007 no se dio de manera generalizada en todo el territorio nacional. Según lo muestran los registros de homicidios del INEGI (2020), las regiones del país con los mayores incrementos en sus tasas fueron las zonas noroeste y noreste de México, donde la primera llegó a registrar 87,2 homicidios por cada 100 mil habitantes en 2010 , mientras que la región noreste tuvo su mayor tasa en 2012, con un nivel de 37,5 homicidios por cada 100 mil habitantes. A nivel nacional, la mayor tasa se había dado en 2011 con un nivel de 23,6, cifra que fue superada en 2017 y 2018 por el incremento de la violencia en las zonas noroeste y occidente (Figura 1).

Según un informe de la Secretaría de Gobernación, de 2010, de los casi 29 mil homicidios vinculados con el crimen organizado y registrados entre el 1 de diciembre de 2006 y el 31 de julio de 2010, un 80\% habían ocurrido en 162 de los 2.456 municipios del país, y habían sido resultado de los enfrentamientos de por lo menos siete cárteles de drogas (SEGOB, 2010). Entre aquellos a los que se atribuyeron los enfrentamientos armados y homicidios en este periodo se encuentran el cártel del Pacífico (o Sinaloa), dirigido en ese entonces por Joaquín Guzmán Loera; el cártel de Tijuana (o de los Arellano Félix), enemigo del cártel de Sinaloa desde los años noventa; el cártel de los Beltrán Leyva, que en un principio estaba ligado estrechamente al cártel de Sinaloa; el cártel de Juárez, dirigido hasta 1997 por Amado Carrillo; el cártel del Golfo y su brazo armado, Los Zetas, que tras una ruptura con el cártel del Golfo formaron su propia organización criminal; y finalmente la Familia Michoacana, con presencia en la región de Tierra Caliente (sEgob, 2010). 
FIgURA 2 | Conflictos y homicidios entre cárteles de drogas mexicanos (1 de diciembre de 2006 al 31 de julio de 2010)

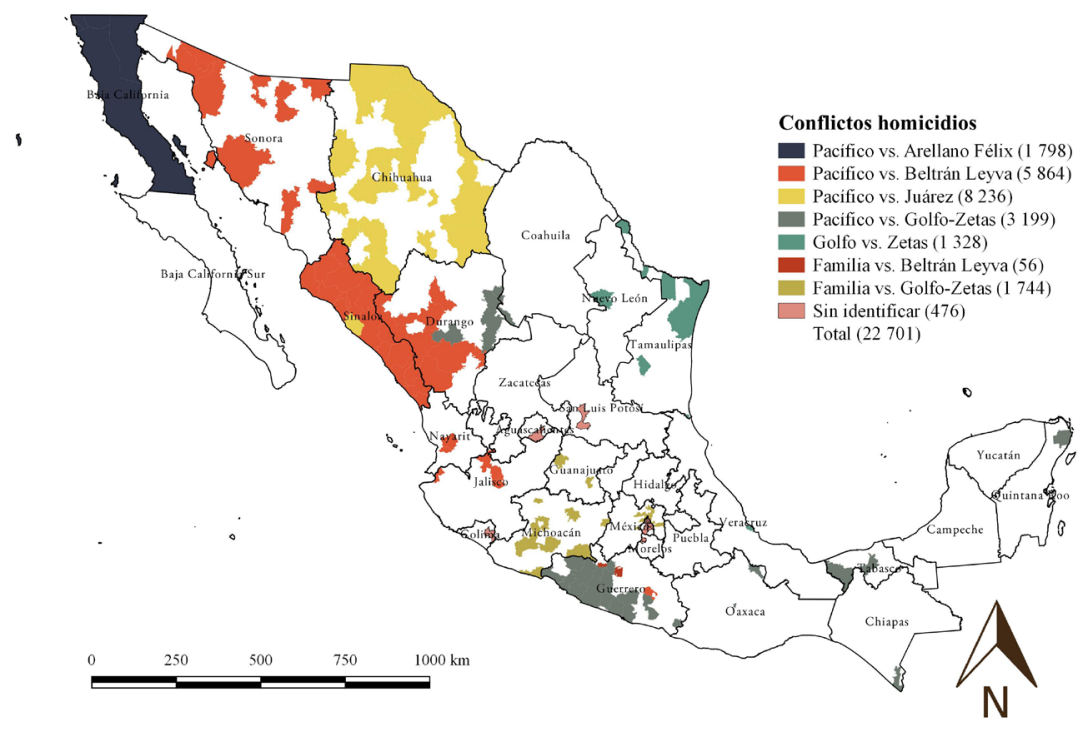

FUENTE: SECRETARÍA DE GOBERNACIÓN (2OIO)

En la Figura 2 se muestran los conflictos por los territorios en las entidades del noroeste y occidente de México asociados a las rutas de tráfico de drogas, tanto de entrada a México como de acceso a EuA. Entre dichos territorios se encuentran la región del Triángulo Dorado, en municipios de Chihuahua, Durango y Sinaloa, además de algunos municipios de Sonora, cuya disputa se daba principalmente entre los cárteles del Pacífico, Juárez y Beltrán Leyva; la región de Tierra Caliente, particularmente en municipios de Guerrero y Michoacán, donde los principales enfrentamientos se dieron entre los cárteles del Pacífico, Golfo-Zetas y Familia Michoacana; y la región noreste, en municipios de Tamaulipas y Nuevo León, en que la división del cártel del Golfo con Los Zetas provocó diversos enfrentamientos por el control de la región (SEGOB, 2010).

Además de las tres regiones mencionadas, destacan los enfrentamientos por los principales puntos de acceso a Eua: Tijuana y Mexicali en Baja California, Ciudad Juárez en Chihuahua, Nuevo Laredo y Reynosa en Tamaulipas y Nogales en Sonora, así como algunos de los principales puertos marítimos del país por donde entran las drogas o precursores procedentes de Asia y Sudamérica, como son Acapulco en Guerrero, Mazatlán en Sinaloa y Lázaro Cárdenas en Michoacán (Schmidt et al., 2017).

La lucha contra el narcotráfico ha sido sesgada por la corrupción e intereses políticos y económicos de los propios gobiernos, que han permitido la producción, comercio y trasiego de drogas en territorio nacional al amparo de diversas instituciones desde el auge del comercio ilegal de drogas entre México y Estados Unidos 
(Chabat, 2005, 2010; Morales Oyarvide, 2011). Esta protección y colusión entre autoridades y grupos criminales ha sido definida por Chabat (2005) como la etapa parasitaria, dirigida a comprar protección e información.

Durante esta etapa parasitaria se ha dado la expansión de diversos cárteles de drogas y el combate entre grupos rivales, tales como la protección del cártel de Guadalajara por instituciones estatales y federales; el crecimiento y vínculo del cártel del Golfo durante el sexenio de Salinas; el combate de grupos contrarios al cártel de Sinaloa durante la denominada GCN; y la expansión del cártel de Jalisco Nueva Generación durante el sexenio de Peña Nieto (Burnett et al., 2010; García Hernández, 2016; Morales Oyarvide, 2011).

\section{Migración y violencia en México}

El estudio de la migración interna e internacional en México se ha concentrado mayoritariamente en la migración económica/laboral al interior de México y hacia EUA, relegando el análisis de otros factores sociales no económicos que pueden llegar a modificar las dinámicas migratorias interna e internacional actuales de diversas regiones. Esto ha cambiado últimamente con estudios que han abordado los efectos de la violencia criminal en México sobre los flujos de migración interna e internacional en años recientes.

$\mathrm{Al}$ respecto, Acosta y Cruz (2016), a partir de modelos de regresión logística para los periodos 1995-2000, 2000-2005 y 2005-2010, muestran que pese a que los factores económicos y demográficos siguen explicando la mayor parte de los flujos de migración interestatal, es a partir del periodo 2005-2010 que la marginación y la violencia tienen un efecto significativo, particularmente en entidades del norte y occidente de México, lo que ha propiciado el aumento de su emigración y la reducción de su inmigración por motivos de violencia.

Gutiérrez y Rivero (2012), a partir de técnicas de análisis contrafactual, examinan la relación entre la violencia y el incremento de la migración interna en los municipios de las doce entidades del país con las mayores tasas de homicidios en 2010. Al respecto, encuentran un efecto causal y focalizado en regiones del norte y occidente de México, lo que es explicado por el aumento de los desplazamientos internos forzados por la violencia. Por su parte, Ramírez y Meza (2012), mediante modelos logísticos, determinan un incremento en las probabilidades de que un hogar reciba remesas de EUA, tenga un migrante en EUA o un migrante retornado de ese país, como resultado de un aumento en la violencia municipal para el periodo 2005-2010.

El Consejo Nacional de Población (CONAPO, 2019) establece la correlación espacial entre tasas de homicidios municipales en 2015 y tasas netas de migración municipales para el periodo 2010-2015, a partir del índice local bivariado de Moran, y determina clústeres de municipios con altas tasas de homicidios y altas tasas netas de migración en los límites de Sinaloa, Chihuahua y Sonora, en la región de Tierra Caliente, además de regiones en Chiapas, Guanajuato, Tamaulipas y Nuevo León. 
Finalmente, Massey et al. (2020), a partir del Mexican Migration Project ${ }^{2}$ y del uso de modelos de historias de eventos en tiempo discreto, establecen el efecto de la probabilidad de que un hogar tenga un migrante interno, internacional o de retorno como resultado del incremento de la violencia a nivel municipal. Muestran al respecto que la violencia incrementa la migración interna, pero no encuentran efectos significativos sobre el aumento de la migración internacional indocumentada.

Si bien estos estudios establecen diferentes efectos de la violencia tanto para la migración interna como para la migración internacional en diferentes periodos, en su mayor parte coinciden en que el efecto de la violencia no se da de manera directa, sino en forma de $U$ invertida $(\cap)$, pues no es hasta que se supera un nivel o umbral de violencia que la gente decide migrar, nivel en el que los costos sociales y económicos de permanecer en los lugares de residencia habitual son mayores a los costos sociales y económicos de migrar. Tal situación ha sido también abordada por investigaciones en países de Asia, África y América, incluidas las de Bariagaber (1997), Moore et al. (2004) y Morrison (1993).

Ante los altos niveles de violencia en algunas regiones de México, resulta necesario analizar la asociación espacial que puede llegar a existir entre estas regiones y los flujos de migración interna, particularmente en aquellos municipios donde se han registrado las mayores tasas de homicidios en México. El propósito de tal enfoque es indagar sobre el aumento de la migración interna a causa de los desplazamientos internos forzados por violencia e inseguridad, así como de los lugares de destino de estos posibles migrantes no económicos, que pueden llegar a ser distintos a los de los migrantes motivados por cuestiones económico-laborales. Desde esta perspectiva, el análisis de la violencia tanto en los flujos de emigración interna como en los flujos de inmigración interna, antes, durante y después de la GCN, contribuye a visibilizar los efectos de la violencia en la dinámica migratoria tanto de los municipios expulsores con altos niveles de violencia como en los municipios receptores de estos migrantes, así como las consecuencias de la posible reducción de la inmigración en municipios a causa de sus altos niveles de violencia en ańos recientes.

\section{Datos}

Dada la falta de datos específicos sobre desplazamientos internos forzados por motivos de violencia e inseguridad, en este trabajo se analizan los flujos de origen y destino de la migración interna municipal para los periodos 1995-2000, 2005-2010 y 2010 2015, particularmente de los municipios con altos niveles de violencia (definidos como el $20 \%$ con mayores tasas de homicidios) a partir de los microdatos de los Censos de Población y Vivienda (CPV) de 2000 y 2010, y de la Encuesta Intercensal (EIC) 2015, utilizando el municipio de residencia de las personas cinco años atrás

El Proyecto de Migración Mexicana (Mexican Migration Project, MMP), creado en 1982 como un esfuerzo binacional entre México y EUA para ampliar la comprensión del proceso de la migración mexicana a los Estados Unidos, tiene su sede en la Universidad de Princeton (Nueva Jersey, EUA). https://mmp.opr.princeton.edu/ 
para crear el indicador de migración. ${ }^{3}$ Estos datos constituyen los más recientes que ofrecen información a nivel nacional, estatal y municipal sobre los flujos de migración interna en México, así como diversas características socioeconómicas, demográficas y geográficas de las personas migrantes y no migrantes (INEGI, 2018a, 2018b).

Las fuentes se complementan con los registros administrativos del INEGI (2020) sobre los homicidios asentados en los certificados de defunción, que son accesibles por años y municipios del país desde 1990 hasta 2019. Este indicador de violencia ofrece un panorama más amplio del fenómeno en comparación con otras fuentes de datos, como la del Sistema Nacional de Seguridad Pública que, pese a tener una base mensual de las carpetas de investigación registradas por las Procuradurías y Fiscalías Generales de los estados, únicamente cuenta con información desagregada a nivel municipal sobre el número de víctimas de homicidios desde 2011.

Los homicidios, y en particular las tasas de homicidios, han sido utilizadas por diversas organizaciones (Institute for Economics and Peace [IEP], 2018; Organización Mundial de la Salud [oms]), 2002; United Nations Office on Drugs and Crime [unODC], 2014) e investigaciones (Alvarado \& Massey, 2010; Enamorado et al., 2014; Gutiérrez \& Rivero, 2012; Ramírez \& Meza, 2012) como indicador de la violencia en los países, regiones, estados y municipios, dado que tienen un impacto significativo sobre la percepción de inseguridad y violencia que las personas viven en sus entornos. Una razón adicional es que este delito, el homicidio, muestra un menor subregistro comparado con otros delitos, y que para el caso de México llega a representar hasta el 93,2\% de los delitos cometidos (INEGI, 2019).

\section{Métodos}

La herramienta básica para determinar la procedencia y destino de los migrantes internos por municipios en un periodo determinado es la matriz de origen-destino, la cual se construye con la pregunta del municipio de residencia cinco años atrás, lo que permite determinar los municipios en los que vivían las personas cinco años atrás y el municipio en que residen al momento del levantamiento del censo o encuesta. La diagonal principal de la matriz (I) corresponde a la población municipal que no ha migrado en el periodo (Tabla 1).

TABLA I | Matriz de origen-destino

\begin{tabular}{|c|c|c|c|c|c|}
\hline $\mathbf{O} / \mathbf{D}$ & $\mathbf{D}_{1}$ & $\mathbf{D}_{2}$ & $\mathbf{D} \ldots$ & $\mathbf{D}_{\mathrm{N}}$ & ORIGEN TOTAL \\
\hline $\mathrm{O}_{1}$ & $\mathrm{I}_{11}$ & & & & \\
\hline $\mathrm{O}_{2}$ & & $\mathrm{I}_{22}$ & & & \\
\hline $\mathrm{O}_{\mathrm{O}}$ & & & $\ldots$ & & \\
\hline Destino Total & & & & & Flujo Total \\
\hline
\end{tabular}

O: MUNICIPIO DE RESIDENCIA CINCO AÑos ATRÁs

$\mathrm{D}_{\mathrm{L}}$ : MUNICIPIO DE RESIDENCIA ACTUAL

I: PERSONAS QUE VIVEN EN EL MISMO MUNICIPIO EN EL QUE RESIDÍAN 5 AÑos ATRÁS

FUENTE: ELABORACIÓN PROPIA

3 El periodo 2000-2005 queda fuera del análisis, pues no se usó el Conteo de Población 2005 al solo contener información de la entidad y país de residencia cinco ańos atrás, por lo que no es posible realizar un análisis municipal de la migración interna. 
Una de las desventajas de las fuentes de datos utilizadas es que únicamente dan cuenta de las migraciones finales en un periodo determinado, dejando fuera el resto de los movimientos que pudieron darse entre periodos. No obstante, su uso se debe a que ofrecen información con representatividad municipal, estatal y nacional, además de que permiten reconstruir los flujos migratorios municipales por quinquenios.

Respecto al análisis de los municipios más violentos del país, se seleccionan a partir de sus tasas de homicidios quinquenales, las cuales se calculan con la fórmula indicada a continuación, para posteriormente seleccionar el $20 \%$ de los municipios con las mayores tasas de homicidios para cada periodo.

$$
\mathrm{T} \text { Homicidios }=\left(\frac{\# \text { de homicidios en el municipio } X \text { en el periodo } t \text { al } t+4}{\text { Población en el municipio X a mitad del periodo }}\right) \times 1000
$$

Debido a que no se cuenta con datos municipales sobre desplazamientos internos forzados por violencia e inseguridad, se parte del supuesto de que los efectos de la violencia sobre los flujos de migración interna son visibles en el $20 \%$ de los municipios con mayores tasas de homicidios, al tener una mayor proporción de habitantes que han superado el denominado umbral de violencia (Alvarado \& Massey, 2010; Moore \& Shellman, 2004; Morrison, 1993; Ramírez \& Meza, 2012; Rodríguez Chávez, 2020), el cual provoca que gran cantidad de personas migren al ser mayores los costos de permanecer en sus lugares de residencia habitual que los de migrar. Pese a que no podemos afirmar que todas las migraciones de dichos municipios sean resultado de desplazamientos forzados, suponemos que, en estos casos, las características generales de las personas migrantes serán diferentes de aquellas migrantes de municipios con bajos niveles de violencia.

Para el análisis de la asociación espacial entre municipios según su nivel de violencia y flujos de migración, se utilizan mapas de indicadores locales bivariados de correlación espacial, o BiLISA, que refieren a la interacción de dos variables distintas en el espacio mediante el uso de la matriz de pesos geográficos para determinar la vecindad entre observaciones y variables. Estos indicadores muestran la relación entre el valor de una variable $\boldsymbol{x}$ en el espacio y el promedio de los valores vecinos para otra variable $\boldsymbol{y}$, en donde ambas variables son estandarizadas para su cálculo (Anselin, 2019).

$$
I_{B, i}=c x_{i} \sum_{j} w_{i j} y_{j}
$$

donde:

$\mathrm{Cx}_{\mathrm{i}}$ : es el valor de la variable $\boldsymbol{x}$ localizada en $\mathrm{i}, \mathrm{x}_{\mathrm{i}}$

$\sum_{\mathrm{j}} w_{\mathrm{ij}} y_{\mathrm{j}}$ es el promedio de los valores de los vecinos para la variable $\boldsymbol{y}$ (o el rezago espacial)

$\mathrm{w}_{\mathrm{ij}}$ es la matriz de pesos geográficos que determina la vecindad o no entre observaciones $^{4}$

4 Se utiliza una matriz de reina de primer orden de contigüidad, que define a los municipios vecinos como aquellos que comparten fronteras o vértices en común. 
Los clústeres observados son una combinación de ambas variables, donde se identifican cuatro tipos: municipios o unidades espaciales en que los valores de las variables propuestas son disímiles (clústeres bajoalto y altobajo) y municipios o unidades espaciales donde los valores de las dos variables propuestas son similares (clústeres altoalto y bajobajo); además, se identifica si estos grupos son estadísticamente significativos a distintos niveles (Anselin, 2019; Sánchez-Peña, 2012).

\section{Resultados}

Relación espacial entre la migración interna y la violencia municipal: 1995-2015 Como se observa en la Figura 3, las regiones asociadas con altas tasas de homicidios y emigración, además de bajas tasas de inmigración, para los tres periodos analizados se localizan particularmente en el Triángulo Dorado ampliado, que comprende municipios serranos de Chihuahua, Durango, Sinaloa y Sonora, y una segunda región en Tierra Caliente ampliada, en las entidades de Michoacán y Guerrero, además de municipios vecinos del Estado de México y Jalisco. Para el periodo 1995-2000, y en menor medida para el periodo 2005-2010, también se observó una región con características similares en municipios costeros de Oaxaca y Guerrero, la cual dejó de ser significativa en el periodo 2010-2015. Este fue un caso contrario al de la región comprendida por municipios de la frontera noreste de Nuevo León y Tamaulipas, que no mostró altas tasas de violencia asociadas a altas tasas de emigración y bajas tasas de inmigración interna sino hasta el periodo 2005-2010, situación que para el periodo 2010-2015 se extendió a gran parte de los municipios del norte de Nuevo León y Tamaulipas.

Respecto a su contraparte, es decir, regiones con bajas tasas de homicidios asociadas a altas tasas de inmigración y bajas tasas de emigración, solo se observa una región que muestra ser significativa para los periodos 1995-2000 y 2005-2010, la cual comprende municipios de Nuevo León y Coahuila, aunque posteriormente esta zona se vio reducida y acotada al noroeste de Coahuila y sur de Nuevo León. Se observan regiones con características dispares a las anteriores, tales como la frontera norte de Sonora que, pese a mostrar altas tasas de homicidios, también presenta altas tasas de inmigración y emigración interna desde el periodo 2005-2010. Se registran, además, regiones con bajas tasas de homicidios, bajas tasas de emigración y bajas tasas inmigración localizadas en la península de Yucatán, en el centro de México; y para el periodo 2005-2010, en el centro de Chiapas. 
FIGURA 3 | Correlación espacial (BiLIsa) entre tasas de homicidios y tasas de emigración e inmigración interna municipales por periodo
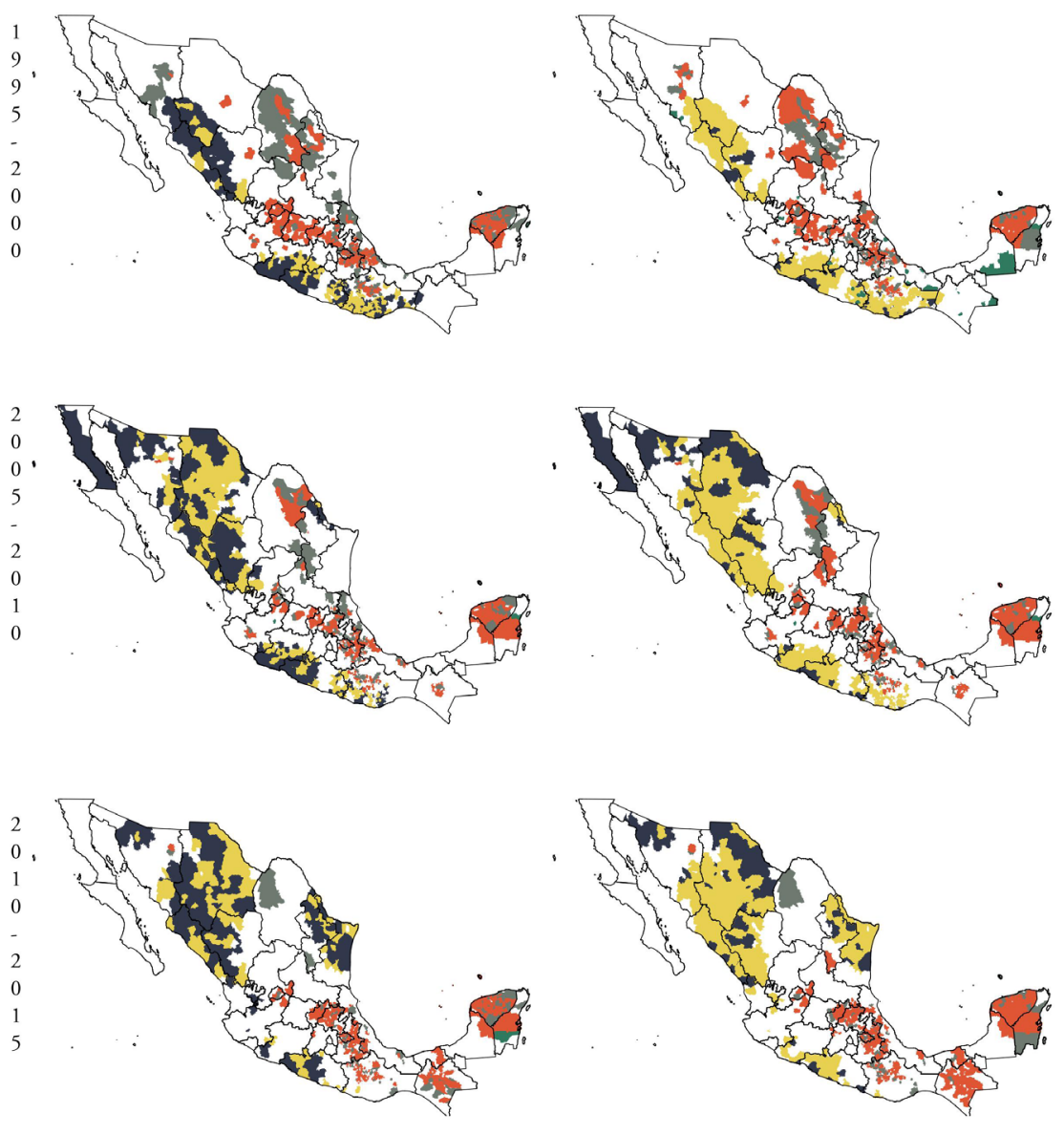

AltaViolencia/AltaEmigración o Inmigración
BajaViolencia/BajaEmigración o Inmigración

AltaViolencia/BajaEmigración o Inmigración

BajaViolencia/AltaEmigración o Inmigración

FUENTE: ELABORACIÓN PROPIA CON DATOS DEL INEGI (2020), CPV 2000 Y 20 IO, EIC 20 I 5 Y SOFTWARE GEODA V I.I 2

Regiones del país con altos niveles de violencia: 1995-2015

En el análisis de los mapas de correlación espacial entre tasas de migración y tasas de homicidios (Figura 3), se identificaron tres regiones del país en donde los altos niveles de homicidios parecen estar asociados a altas tasas de emigración y bajas tasas de inmigración: la primera localizada al noroeste de México en municipios serranos de Chihuahua, Sinaloa, Durango y Sonora, zona aquí denominada Triángulo Dorado ampliado; una región más al occidente de México en municipios serranos de Guerrero, Michoacán y Estado de México, identificada como Tierra 
Caliente ampliada; y una región al noreste del país surgida en el periodo 20052010 en municipios fronterizos de Nuevo León y Tamaulipas, nombrada como Frontera Noreste. Su delimitación quedó conformada por la selección de municipios vecinos dentro de las regiones que hayan mostrado altas tasas de violencia (quintil V) durante por lo menos dos de los tres periodos seleccionados, lo que permite hacer comparaciones de estas regiones entre distintos periodos de análisis.

Además de las regiones seleccionadas, se localizaron cuatro más -Tijuana, Frontera Noroeste, Puerto Vallarta y Frontera Sur-, las cuales, pese a no mostrar una asociación y correlación espacial significativas, también se caracterizan por incluir municipios con altas tasas de violencia en los tres periodos seleccionados y que, por su cercanía geográfica, económica, redes migratorias y vínculos con las rutas de drogas terrestres hacia Estados Unidos, pueden llegar a estar asociadas con las tres regiones propuestas en el análisis (Figura 4).

A partir de las matrices de origen-destino por quinquenios, se ubican los lugares a los que se dirigieron los emigrantes de las tres regiones propuestas para los periodos seleccionados, cuyos flujos fueron cartografiados con el propósito de visualizar la distribución y principales regiones de emigración, así como los cambios en los patrones y volúmenes de los migrantes a lo largo de los tres periodos seleccionados. Estas tres regiones destacan, pues además de ser las zonas del país con los mayores incrementos de violencia en las últimas dos décadas, forman parte de las rutas principales de drogas a euA desde los ańos noventa (segob, 2010). Asimismo, Tierra Caliente ampliada y Triángulo Dorado ampliado están entre las principales regiones de producción de drogas en México. Por tanto, el control de estos territorios por parte de los cárteles resulta estratégico para acaparar el mercado de drogas estadounidense.

FIGURA 4 | Regiones seleccionadas con altos niveles de violencia, 1995-2015

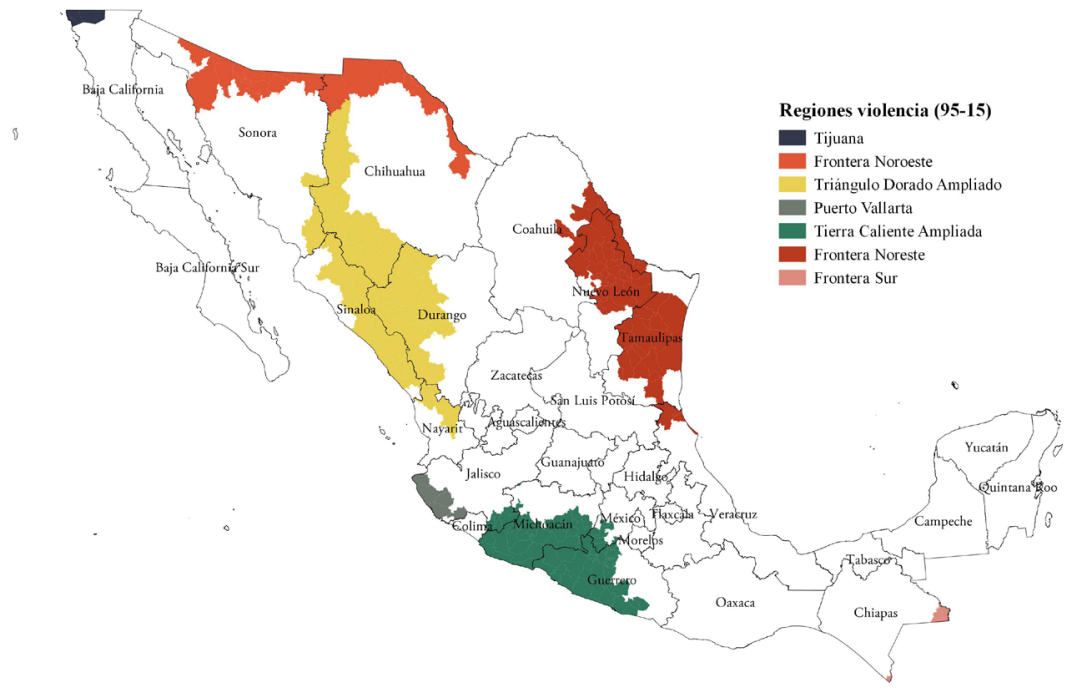

FUENTE: ELABORACIÓN PROPIA CON REGISTROS ADMINISTRATIVOS DEL INEGI (2O2O) Y SOFTWARE QGIS 2.I 8 


\section{Triángulo Dorado ampliado}

En la Figura 5 se muestran los flujos de emigración de la región Triángulo Dorado ampliado, integrada por 45 municipios: 15 de Chihuahua, 14 de Durango, 11 de Sinaloa, 3 de Nayarit y 2 de Sonora. La emigración de esta región se dirige predominantemente hacia municipios del noroeste de México, particularmente hacia aquellos de las zonas metropolitanas de Tijuana, Mexicali, Durango y Culiacán (entre el $21 \%$ y $28 \%$ del total), donde existe una mayor demanda de mano de obra para la industria maquiladora de exportación (Tijuana y Mexicali), lo que puede llegar a explicar la mayor parte de su flujo migratorio. Además, se observan flujos importantes hacia Chihuahua y Juárez en el Estado de Chihuahua, Hermosillo en Sonora, Ensenada en Baja California, Los Cabos en Baja California Sur, Mazatlán y Ahome en Sinaloa y Zapopan en Jalisco.

Si bien para el periodo 1995-2000, Tijuana, Mexicali y Juárez se posicionaban entre las principales metrópolis a las que se dirigían los migrantes del Triángulo Dorado ampliado, fue durante el periodo 2005-2010 que se vio reducido su flujo de emigración, lo que coincide con el aumento de la violencia en el noroeste de México desde 2007, resultado principalmente de los enfrentamientos entre los cárteles de Sinaloa y de Juárez por el control del territorio y rutas de drogas hacia EUA (sEgOB, 2010). A ello se suma la crisis económica de 2008-2009, cuyos impactos tuvieron mayores repercusiones para la industria maquiladora de exportación, de gran importancia en la frontera norte de México (Barrios de la O, 2016).

Pese a que en el periodo 2005-2010 se dio una reducción en los flujos de emigración interna del Triángulo Dorado ampliado, propiciada por los descensos registrados en sus principales destinos, esto no ocurrió para zonas metropolitanas como Los Cabos en Baja California Sur, Mazatlán en Sinaloa y la capital de Chihuahua, que vieron incrementar sus flujos de emigración procedentes del Triángulo Dorado ampliado. Esto último puede estar asociado a la demanda de mano de obra en los sectores turístico y manufacturero, pero también a una mayor percepción de seguridad respecto a sus lugares de origen (Durin, 2012; Martínez, 2016).

Posteriormente, en el periodo 2010-2015, la emigración de la región Triángulo Dorado ampliado tuvo un incremento respecto al periodo previo, donde se observan crecimientos hacia Mexicali, Culiacán, Durango y Hermosillo, capitales de las entidades del noreste de México. Ello coincide con el incremento y expansión de la violencia como resultado de la lucha entre los cárteles de Sinaloa y los Beltrán Leyva, pero también con los enfrentamientos del cártel de Sinaloa contra el cártel de los Arellano-Félix en Tijuana y el cártel de Juárez en prácticamente todo el Estado de Chihuahua, estancando los flujos migratorios hacia Ciudad Juárez y la capital del estado, territorios que entre 2010-2012 experimentaron las mayores tasas de homicidios en el país (Barrios de la O, 2016; Durin, 2012).

Lo anterior sugiere que el crecimiento de la emigración interna hacia las capitales de las entidades del noroeste de México durante los periodos 2005-2010 y 20102015 se vio intensificado por el aumento de los desplazamientos forzados en la región, cuyo propósito era salvaguardar las vidas de los involucrados, tal y como lo han documentado diversos medios y organizaciones de la sociedad civil (Animal

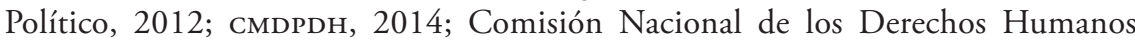


[CNDH], 2016; Martínez, 2016), además de fuentes de datos como la Encuesta de Percepción Ciudadana sobre Inseguridad en Ciudad Juárez (Centro de Investigaciones Sociales [CIS], 2009). Aunque la migración de esta región es mayoritariamente intrarregional, asociado en parte a su larga historia migratoria y a la presencia de redes migratorias resultado de los procesos económicos y laborales ligados a la industria maquiladora de exportación desde mediados de los ańos ochenta, y más recientemente al desarrollo de zonas turísticas cercanas a la región (Sobrino, 2010), es importante resaltar que los flujos de emigración e inmigración se vieron afectados por los niveles crecientes de violencia, tanto de los municipios de origen como de algunos de sus principales lugares de destino (CIs, 2009; СмDPDH, 2014).

\section{FIGURA 5 | Flujos de emigración interna municipal de la región Triángulo Dorado ampliado}
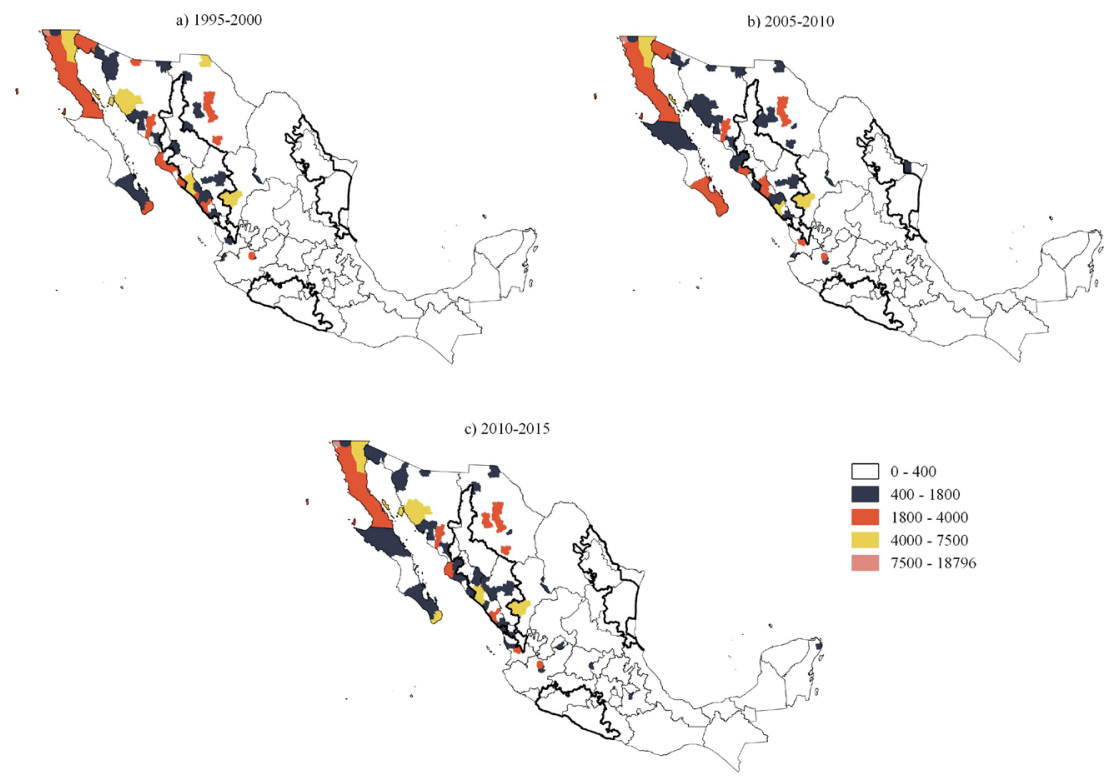

FUENTE: ELABORACIÓN PROPIA CON DATOS DE LOS CPV 2000 Y 20 IO, EIC 20 I 5 Y SOFTWARE QGIS 2. I 8

\section{Tierra Caliente}

La región de Tierra Caliente ampliada (Figura 6), se constituye por 70 municipios de Michoacán (30), Guerrero (29), Estado de México (7) y Jalisco (4), y su emigración se ha dirigido especialmente hacia la región del Pacífico y de la península de Baja California, particularmente a los municipios de Morelia, Lázaro Cárdenas, Acapulco, Tijuana, Chilpancingo, Los Cabos y Zihuatanejo (entre el 22\% y el 24\% de su emigración). También muestra flujos importantes en algunos periodos hacia municipios como Cuernavaca en Morelos, Toluca en Estado de México, La Paz en Baja California Sur y Benito Juárez en Quintana Roo. 
A pesar de que la región, particularmente la centrada en las partes serranas de Guerrero, Michoacán y Estado de México, muestra conflictos y presencia del narco desde mediados del siglo xx (Guerra Mazo, 2018), no fue hasta inicios del siglo XxI que la división y enfrentamiento de los distintos grupos criminales, como el cártel de Sinaloa, Golfo-Zetas y la Familia Michoacana, entre otros, incrementaron la violencia e inseguridad de la región. Esto se tradujo en delitos como homicidios, secuestros y extorsiones, lo que provocó el hartazgo de sectores de la población que se levantaron en armas mediante la creación de grupos de autodefensa, cuyo objetivo inicial era repeler a los grupos criminales activos en sus territorios (Cherem Maus, 2016).

Los flujos de emigración intrarregional de Tierra Caliente ampliada muestran descensos constantes inclusive antes del periodo 1995-2000, puesto que grandes cantidades de personas ya habían optado por migrar de manera definitiva, motivadas por cuestiones económicas y laborales asociadas tanto a las crisis económicas de finales del siglo xx (Sobrino, 2010), como a las redes migratorias fomentadas por los programas braceros durante la SGM (Durand, 2016). Sin embargo, la creciente violencia en las comunidades de origen, resultado de los enfrentamientos entre el cártel del Pacífico contra el cártel del Golfo-Zetas y la ruptura entre el cártel del Golfo-Zetas y la Familia Michoacana (SEGOB, 2010), contribuyeron a que la migración internacional, que inicialmente era de carácter circular, se tornara cada vez más permanente.

Como resultado de los continuos incrementos de la violencia y de la precarización económica de la región, era de esperarse que los flujos de emigración hacia municipios cercanos y/o con altos niveles de violencia se hubieran reducido, como fue el caso en Lázaro Cárdenas, Uruapan y Morelia en Michoacán, y Chilpancingo e Iguala en Guerrero durante el periodo 2005-2010. De igual forma, en destinos más alejados, que en el pasado mostraban flujos importantes de emigración procedentes de Tierra Caliente ampliada -entre ellos, Puerto Vallarta y Guadalajara en Jalisco, Ciudad Juárez en Chihuahua, Nuevo Laredo en Tamaulipas y Manzanillo en Colima-, dichos movimientos poblacionales se vieron reducidos por los impactos de la crisis económica de 2008-2009 y el incremento de los niveles de violencia desde 2008.

En contraste, municipios como Acapulco en Guerrero, Los Cabos en Baja California Sur, Toluca en el Estado de México, Bahía de Banderas en Nayarit, Celaya en Guanajuato, Mexicali en Baja California, y Coyoacán y Gustavo A. Madero en la Ciudad de México mostraron incrementos en sus flujos de migración procedentes de Tierra Caliente ampliada para el periodo 2005-2010. La principal motivación hacia estos destinos pudo ser la atracción de mano de obra para la industria maquiladora y para el sector servicios -incluido el turístico-, además de las aparentes mejores condiciones de seguridad en algunos de esos destinos.

En el periodo 2010-2015, se observa una diversificación de destinos hacia otros municipios y entidades cercanos a la región, pero también hacia regiones cada vez más alejadas, tales como la península de Yucatán, Benito Juárez en Quintana Roo y Los Cabos en la península de Baja California. Además, se detectan reducciones en algunos de sus flujos principales para los municipios de Morelia, Lázaro Cárdenas y Uruapan en Michoacán, Cuernavaca en Morelos, Tijuana en Baja California, La Paz 
en Baja California Sur, y Acapulco y Chilpancingo en Guerrero, destinos que en su mayor parte mostraron aumentos en sus niveles de violencia.

\section{FIGURA 6 | Flujos de emigración interna municipal de la región Tierra Caliente ampliada}
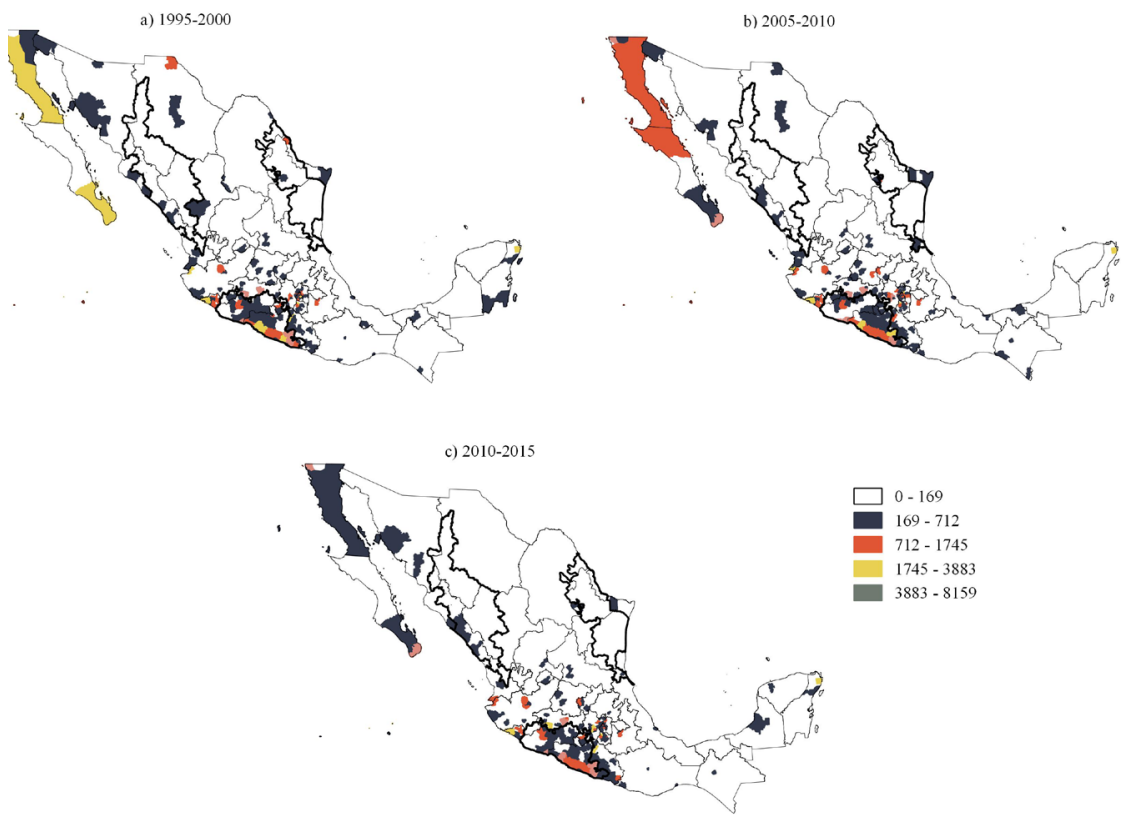

FUENTE: ELABORACIÓN PROPIA CON DATOS DE LOS CPV 2000 Y 20 IO, EIC 20 I 5 Y SOFTWARE QGIS 2 . I 8

\section{Frontera Noreste}

Por último, para la región nombrada como Frontera Noreste, conformada por 69 municipios (35 de Nuevo León, 25 de Tamaulipas, 6 de Coahuila y 3 de Veracruz), a diferencia de las dos regiones anteriores, el incremento de su violencia se dio particularmente desde finales de 2009 y principios de 2010, cuando Los Zetas, el grupo armado del cártel del Golfo, se separó y comenzó una lucha por el control de los territorios y rutas locales de drogas hacia Estados Unidos, lo que propició el incremento de los homicidios en la región y el alza de otros delitos, como los secuestros, extorsiones y los llamados narco-bloqueos (Durin, 2012; SEGOB, 2010).

Inicialmente, el incremento de la violencia en la región provocó la migración de familias con alto poder adquisitivo hacia ciudades vecinas de EUA, mediante el uso de visas de negocios y de turista. No obstante, el aumento no solo de la violencia, sino también de las amenazas directas de los grupos criminales contra la población en general, provocó la salida de cientos de familias y de localidades enteras en algunos municipios fronterizos de Nuevo León y Tamaulipas desde finales de 2010 (Durin, 2012).

En la Figura 7 se muestran los flujos de destino de la región para sus migrantes internos en los tres periodos analizados, donde se observa que las principales zonas 
metropolitanas a las que se dirigieron fueron las de Monterrey, Saltillo, Tampico y Reynosa-Matamoros, y en especial a los municipios de General Escobedo, Guadalupe, Juárez, Apodaca, San Nicolás de los Garza, Santa Catarina y Monterrey en Nuevo León, y en Victoria, Reynosa y Matamoros en Tamaulipas para los tres periodos seleccionados (entre el 41 y el 58\% del total de su emigración), lo que da cuenta de que la mayor parte de su migración interna se dirigió hacia municipios cercanos.

Para el periodo 1995-2000, sus principales flujos fueron intrarregionales a los municipios de General Escobedo, Apodaca, Guadalupe, San Nicolás de los Garza, Juárez, Santa Catarina y Monterrey en Nuevo León, además de Reynosa, Matamoros y Tampico en Tamaulipas (55\% del total), los cuales representan zonas de gran importancia económica y laboral para la región. Empero, fue a partir del periodo 2005-2010 -época en que los incrementos de la violencia ocurridos en la mayor parte de estos municipios fueron atribuidos al cártel Golfo-Zetas- que algunos de estos municipios, como San Nicolás de los Garza, Guadalupe, San Pedro Garza García, Tampico, Monterrey y Matamoros, vieron reducidos sus flujos de migración procedentes de Frontera Noreste.

En el caso opuesto, municipios de la región como García, Juárez, General Zuazua, General Escobedo, Santa Catarina y Carmen en Nuevo León mostraron incrementos en sus flujos de migrantes. Inclusive, municipios más alejados -como Saltillo y Ramón Arizpe en Coahuila, la capital de San Luis Potosí, la alcaldía de Benito Juárez en la Ciudad de México y Fresnillo en Zacatecas- incrementaron la migración procedente de la región Frontera Noreste para el periodo 2005-2010.

En el periodo 2010-2015 se registró el mayor incremento de la emigración interna municipal de la región, lo que coincide con la fractura de la alianza de Los Zetas con el cártel del Golfo. Esta situación propició una serie de enfrentamientos violentos por el control de los territorios locales y de las rutas de drogas a EUA en prácticamente toda la región, lo que se tradujo en un alza de las tasas de homicidios, hasta llegar a sus máximos históricos durante el periodo.

Los principales lugares de destino entre 2010 y 2015 fueron los municipios de García, General Escobedo, Guadalupe, Juárez, Apodaca, Pesquería San Nicolás de los Garza, Carmen y Monterrey en Nuevo León y Victoria en Tamaulipas. No obstante, García, Pesquería, Guadalupe, Carmen, Monterrey, San Pedro Garza García y Ciénega de Flores en Nuevo León fueron los municipios con los mayores incrementos absolutos desde los años 2005-2010, en tanto que las mayores reducciones absolutas se dieron en General Zuazua, Juárez, General Escobedo, Santa Catarina y Apodaca en Nuevo León; Nuevo Laredo, Matamoros y Altamira en Tamaulipas y Saltillo en Coahuila.

Durante el periodo 2010-2015 se tuvo conocimiento, mediante diversos medios, del desplazamiento masivo y forzado de cientos de familias en localidades de la región Frontera Noreste. Tales fueron los casos de Ciudad Mier y Ciudad Guerrero en Tamaulipas, donde grupos criminales asociados al cártel del Golfo y de Los Zetas asesinaron a decenas de personas e incendiaron casas de las comunidades, amenazando al resto de las familias para que abandonaran sus hogares, situaciones que se continuaron repitiendo a lo largo de los ańos señalados en otras comunidades de Nuevo León y Tamaulipas (Durin, 2012; Rubio \& Pérez, 2016). 


\section{FIGURA 7 | Flujos de emigración interna municipal de la región Frontera Noreste}
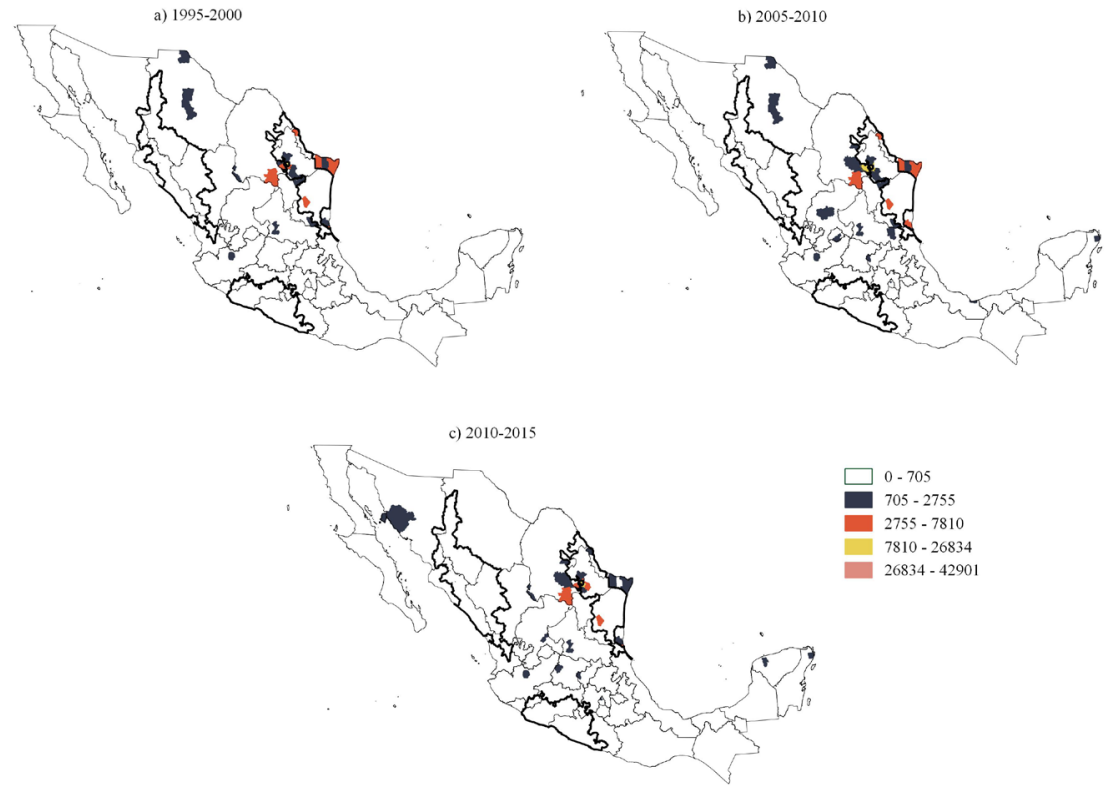

FUENTE: ELABORACIÓN PROPIA CON DATOS DE LOS CPV 2000 Y 20 IO, EIC 20 I 5 Y SOFTWARE QGIS 2 . I 8

\section{Conclusiones}

La violencia y la migración interna en México desde inicios del siglo xxi muestran una asociación significativa, particularmente en algunas regiones del norte y occidente del país donde se da una importante presencia de grupos del narcotráfico. Tal asociación es también resultado de la estrategia de seguridad federal denominada "Guerra contra el Narcotráfico" iniciada a finales de 2006 por el expresidente Felipe Calderón, consistente en el enfrentamiento directo de las fuerzas armadas contra los grupos criminales, y en especial contra algunos de los principales cárteles de drogas en México, que provocó el abatimiento de algunos de sus líderes y la división entre los cárteles por el control de los territorios y de las rutas de cultivo, producción, distribución, venta y trasiego de diversos tipos de drogas. A partir del periodo 20052010, se observa una asociación espacial significativa entre municipios y regiones con altos niveles de violencia cercanos a regiones con altas tasas de emigración interna y bajas tasas de inmigración interna, lo que puede dar evidencia sobre los efectos de la violencia en la dinámica migratoria interna en México resultante de los desplazamientos internos forzados por violencia e inseguridad en ańos recientes.

El análisis de la correlación espacial entre las regiones del país con altos niveles de violencia, altas tasas de emigración y bajas tasas de inmigración interna municipal arrojó tres regiones de estudio: Triángulo Dorado ampliado, localizada al noroeste de México; Tierra Caliente ampliada, situada en el occidente de México; 
y Frontera Noreste, ubicada en Nuevo León y Tamaulipas. Las dos primeras se caracterizan por la presencia e historia en la formación de los principales cárteles de drogas mexicanos y de algunos de sus líderes, así como en el cultivo de marihuana y amapola desde los años cuarenta, lo que, junto con sus condiciones geográficas, climáticas y sociales, ha representado para los cárteles mexicanos las regiones de mayor producción de drogas en el país. Las tres regiones analizadas forman parte de las principales rutas terrestres de trasiego de drogas hacia EUA, las cuales vieron incrementar su importancia internacional tras la alianza entre los cárteles mexicanos y los colombianos en los ańos noventa como respuesta al declive de la ruta del Caribe que, hasta ese momento, los colombianos usaban para introducir cocaína en el mercado estadounidense.

Mediante el análisis de la matriz de origen-destino de los migrantes procedentes de estas tres regiones se identificaron cambios en sus patrones migratorios, resultado de factores económicos y laborales, como la crisis económica de 2008-2009, y de factores sociales, como las redes migratorias formadas tras las migración del campo a las ciudades en la segunda mitad del siglo xx; pero también de cambios en la seguridad, resultado del aumento de la violencia en estas regiones y en algunos de sus principales destinos, lo que ha propiciado la reducción de los flujos a municipios con alta violencia y el incremento hacia municipios con mejores condiciones económicas, sociales y de seguridad.

El análisis presentado constituye un primer acercamiento a la geografía de la violencia en México y sus posibles efectos sobre la dinámica migratoria interna, el cual permite visibilizar el incremento de los flujos de emigración y la reducción de los flujos de inmigración para las regiones con altos niveles de violencia, algo que no se había analizado de manera conjunta hasta ahora. Sin embargo, este trabajo no está libre de limitaciones metodológicas. Por su naturaleza, opté por acotarme a determinar asociaciones espaciales entre ambos fenómenos, así como el origen y destino de los migrantes internos para las regiones con mayor violencia, pues no será sino hasta los resultados del Censo de Población y Vivienda 2020 que se tendrá información sobre los motivos de las migraciones, incluidos la violencia e inseguridad.

Este análisis no considera efectos causales ni la inclusión de otros factores que pueden llegar a estar asociados con la migración interna municipal, mismos que son objeto de otro estudio. Además, se espera que los municipios con menores niveles de violencia muestren diversas tasas de emigración e inmigración, asociadas particularmente a factores económicos y laborales, tanto de los lugares de origen como del destino, pero no fue objeto de estudio de este análisis. Además, escapa de los alcances de este trabajo el análisis de la corrupción y colusión de los grupos criminales con autoridades locales, estatales y federales, alianzas que pueden llegar a tener impactos geográficos diferenciados en el combate de los cárteles de drogas, propiciando el crecimiento y expansión de aquellos protegidos por los gobiernos, y la reducción y división de grupos rivales.

Por tanto, espero que estos resultados motiven investigaciones que permitan comprender el efecto de otros factores relacionados con la migración interna y de sus posibles efectos espaciales en los municipios cercanos, así como futuros análisis 
de las implicaciones de la violencia en México que ayuden a contribuir en el análisis actual de la dinámica migratoria interna y de la violencia criminal.

\section{Referencias bibliográficas}

Acosta, F. \& Cruz, R. (2016). Factores económicos y sociales asociados a la migración interna en México. En F. Acosta \& R. Cruz (Eds.), Migración interna en México. Tendencias recientes en la movilidad interestatal (pp. 115-148). Colegio de la Frontera Norte, México.

Alvarado, S. \& Massey, D. (2010). In search of peace: structural adjustment, violence and international migration. The Annals of the American Academy of Political and Social Science, 630(1), 137-161. https:/www.ncbi.nlm.nih.gov/pmc/articles/PMC3011825/

Animal Político. (2012). Desplazados del Narco. Animal Político. Website. https://www. animalpolitico.com/especial-desplazados/

Anselin, L. (2019). Local Spatial Autocorrelation (2). GeoDa. An introduction to spatial data analysis. Website. https://geodacenter.github.io/workbook/6b_local_adv/lab6b.html\# bivariate-local-morans-i

Bariagaber, A. (1997). Political violence and the uprooted in the horn of Africa. A study of refugee flows from Ethiopia. Journal of Black Studies, 28(1), 26-42. https://www.jstor. $\mathrm{org} /$ stable/2784892?seq=1

Barrios de la O, M. I. (2016). Movilidad humana en Ciudad Juárez 2007-2012: Transitando de la inmigración laboral a la emigración y desplazamiento forzado. El Colegio de la Frontera Norte, México.

Botello, N., Dávila-Cervantes, C. \& Pardo, A. (2019). Necro-spaces and violent homicides in Mexico. International Journal of Conflict and Violence, 13, 1-14. https://doi. org/10.4119/UNIBI/ijcv.660

Burnett, J., Peńaloza, M. \& Benincasa, R. (2010, mayo 19). Mexico seems to favor Sinaloa cartel in drug war. National Public Radio. https://www.npr.org/2010/05/19/126906809/ mexico-seems-to-favor-sinaloa-cartel-in-drug-war

Centro de Investigaciones Sociales (cIs). (2009). Encuesta de Percepción Ciudadana sobre Inseguridad en Ciudad Juárez (EPCIJ). Universidad Autónoma de Ciudad Juárez, México.

Chabat, J. (2005). Narcotráfico y estado: el discreto encanto de la corrupción. Letras libres. Website. https://www.letraslibres.com/mexico/narcotrafico-y-estado-el-discreto-encan to-la-corrupcion

Chabat, J. (2010). La respuesta del gobierno de Felipe Calderón ante el desafío del narcotráfico: entre lo malo y lo peor. En A. Alvarado y M. Serrano (Coords.), Los grandes problemas de México. XV: Seguridad nacional y seguridad interior (pp. 21-40). El Colegio de México. https://2010.colmex.mx/16tomos/XV.pdf

Cherem Maus, A. (2016). Grupos de autodefensa: sin salida ante la violencia. Instituto Tecnológico Autónomo de México. 
Comisión Mexicana de Defensa y Promoción de los Derechos Humanos (смDpdh). (2014). Desplazamiento interno forzado en México. Comisión Mexicana de Defensa y Promoción de los Derechos Humanos. Website. http://www.cmdpdh.org/publicacionespdf/cmdpdh-desplazamiento-web.pdf

Comisión Nacional de los Derechos Humanos (CNDH). (2016). Informe especial sobre desplazamiento forzado interno (DFI) en México. http://www.cndh.org.mx/sites/all/doc/ Informes/Especiales/2016_IE_Desplazados.pdf

Comisión Nacional de Seguridad (CNs). (2013, enero 10). Acuerdos aprobados en la II Sesión Extraordinaria del Consejo Nacional de Seguridad Pública. Diario Oficial de La Federación, pp. 1-6. http://www.dof.gob.mx/nota_detalle.php?codigo=5284444\&fec ha $=10 / 01 / 2013$

Consejo Nacional de Población (CONAPo). (2019). La violencia como causa de desplazamiento interno forzado. Aproximaciones a su análisis en México. https://www.gob.mx/cms/ uploads/attachment/file/456109/Desplaz_2019_web_color-comp.pdf

Durand, J. (2016). Historia minima de la migración México-Estados Unidos. El Colegio de México. https://doi.org/10.2307/j.ctt1t89k3g

Durin, S. (2012). Los que la guerra desplazó: familias del noreste de México en el exilio. Desacatos, (38, enero-abril), 29-42. http://desacatos.ciesas.edu.mx/index.php/ Desacatos/article/view/269/149

Enamorado, T., López-Calva, L. \& Rodríguez-Castelán, C. (2014). Income inequality and violent crime evidence from México’s Drug War (N.o 6935). http://documents.worldbank.org/ curated/en/236161468299090847/pdf/WPS6935.pdf

García Hernández, J. L. (2016, octubre 13). Académicos: Sólo la corrupción explica que el CJNG se volviera tan poderoso en este sexenio. Sin Embargo. https://www.sinembargo. $\mathrm{mx} / 13-09-2016 / 3091337$

Guerra Mazo, E. (2018). La violencia en Tierra Caliente, Michoacán c. 1940-1980. Estudios de Historia Moderna y Contemporánea de México, 56(julio-diciembre), 59-75. http:// www.revistas.unam.mx/index.php/ehm/article/view/65796/57770

Gutiérrez, E. \& Rivero, E. (2012). Elaboración de diagnóstico: Desplazamiento interno en México. [Documento interno]. En Internal Displacement Monitoring Centre. Versión institucional y resumida en http://cmdpdh.org/temas/desplazamiento/wp-content/ uploads/2019/04/2012005-am-mexico-Mexico-forced-displacement-en-1.pdf

InSight Crime. (2020). México crimen organizado. Perfil de México. Website. https:// es.insightcrime.org/mexico-crimen-organizado/mexico/

Institute for Economics and Peace (IEP). (2018). Indice de datos sobre homicidios ¿Cómo registramos los homicidios en México? https://es.readkong.com/page/ndice-de-datossobre-homicidios-institute-for-economics- 4526274

Instituto Nacional de Estadística y Geografía (INEgi). (2015). Encuesta Nacional de la Dinámica Demográfica 2014. Instituto Nacional de Estadística y Geografía. Website. http://www.inegi.org.mx/est/contenidos/proyectos/encuestas/hogares/especiales/ enadid/enadid2014/default.aspx

Instituto Nacional de Estadística y Geografía (INEGI). (2018a). Censo de Población y Vivienda 1940-2010. Instituto Nacional de Estadistica y Geografía. Website. http://www.inegi. org.mx/est/contenidos/proyectos/ccpv/default.aspx 
Instituto Nacional de Estadística y Geografía (INEGI). (2018b). Encuesta Intercensal 2015. Instituto Nacional de Estadistica y Geografia. Website. www.beta.inegi.org.mx/ proyectos/enchogares/especiales/intercensal/

Instituto Nacional de Estadística y Geografía (INEGI). (2019). Encuesta Nacional de Victimización y Percepción sobre Seguridad Pública. Instituto Nacional de Estadística y Geografia. Website. http://www.beta.inegi.org.mx/proyectos/enchogares/regulares/ envipe/2016/

Instituto Nacional de Estadística y Geografía (INEGI). (2020). Registros administrativos. Estadísticas vitales. Mortalidad. Instituto Nacional de Estadística y Geografía. Website. https://www.inegi.org.mx/sistemas/olap/proyectos/bd/continuas/mortalidad/ defuncioneshom.asp?s=est

Internal Displacement Monitoring Centre (IDMC). (2010). Informe del Observatorio de Desplazamiento Interno del Consejo Noruego para Refugiados sobre el desplazamiento forzado en México a consecuencia de la violencia de los cárteles de la droga. http://www. acnur.org/t3/fileadmin/Documentos/Proteccion/2011/7627.pdf?view=1

Internal Displacement Monitoring Centre (IDMC). (2020). Internal displacement in Mexico. Country information 2019. Internal Displacement Monitoring Centre. Website. https:// www.internal-displacement.org/countries/mexico

Martínez, P. (2016, noviembre 30). Desplazamiento forzado: el saldo oculto de la guerra. Animal Politico. http://www.animalpolitico.com/diez-de-guerra/desplazados.html

Massey, D., Durand, J. \& Pren, K. (2020). Lethal violence and migration in Mexico: An analysis of internal and international moves. Migraciones Internacionales, 11, 1-20. https://migracionesinternacionales.colef.mx/index.php/migracionesinternacionales/ article/download/2282/1537

Moore, W. H. \& Shellman, S. M. (2004). Fear of persecution: Forced migration, 1952-1995. The Journal of Conflict Resolution, 48(5), 723-745. https://doi. org/10.1177\%2F0022002704267767

Morales Oyarvide, C. (2011). La guerra contra el narcotráfico en México. Debilidad del Estado, orden local y fracaso de una estrategia. Aposta. Revista de Ciencias Sociales, (50, juliosept.), 1-35. http://www.apostadigital.com/revistav3/hemeroteca/oyarvide.pdf

Morales Tenorio, G. I. (2019). Cien años de opiáceos en México (p. 26). http://bibliodigitalibd. senado.gob.mx/bitstream/handle/123456789/4399/MESA 2 JORGE JAVIER ROMERO VADILLO.PDF? sequence $=36 \&$ isAllowed $=y$

Morrison, A. (1993). Violence or economics: What drives internal migration in Guatemala? Economic Development and Cultural Change, 41(4), 817-831. https://doi. org/10.1086/452049

Organización Mundial de la Salud (oms). (2002). Informe mundial sobre la violencia y la salud: Resumen. Publicado en español por la Organización Panamericana de la Salud para la Organización Mundial de la Salud. Washington, D.c. https://apps.who.int/iris/ handle/10665/43431?show=full

Ramírez, T. \& Meza, L. (2012). Inseguridad pública y migración internacional en México. En T. Ramírez \& M. A. Castillo (Eds.), El estado de la migración. México ante los recientes desafios de la migración internacional (pp. 269-298). Consejo Nacional de Población, México. 
Rodríguez Chávez, O. (2020). Violencia, desplazamiento interno forzado y dinámica migratoria en México (1995-2015). El Colegio de México.

Rubio, L. \& Pérez, B. (2016, enero 1). Desplazados por violencia. La tragedia invisible. Revista Nexos. Website. http://www.nexos.com.mx/?p=27278

Sánchez-Peña, L. L. (2012). Alcances y límites de los métodos de análisis espacial para el estudio de la pobreza urbana. Papeles de Población, 72(abril/junio), 147-179. https:// rppoblacion.uaemex.mx/article/view/8434/7145

Schmidt, S., Cervera-Gómez, L. \& Botello Mares, A. (2017). México: territorialización de los homicidios. Las razones de la violencia en el norte del país. Realidad, Datos y Espacio. Revista Internacional de Estadistica y Geografía, 8(2), 81-95. https://rde.inegi.org.mx/ rde_21/RDE21.pdf

Secretaría de Gobernación (sEgob), México. (2010). Informe sobre el fenómeno delictivo en México. https://mafiaandco.wordpress.com/2010/08/10/informacion-sobre-el-feno meno-delictivo-en-mexico/

Sobrino, J. (2010). Migración interna en México durante el siglo XX. Consejo Nacional de Población (CONAPO), México. www.conapo.gob.mx/es/CONAPO/Migracion_interna _en_Mexico_durante_el_siglo_XX\%0D

United Nations Office on Drugs and Crime (UNODC). (2014). Global study on homicide 2013. Trends, context, data. https://www.unodc.org/documents/gsh/pdfs/2014_GLOBAL_ HOMICIDE_BOOK_web.pdf 